\title{
Co-expression of SpSOS1 and SpAHA1 in transgenic Arabidopsis plants improves salinity tolerance
}

Yafei Fan ${ }^{1+}$, Xiaochang Yin ${ }^{1+}$, Qing Xie ${ }^{1}$, Youquan Xia ${ }^{1}$, Zhenyu Wang ${ }^{1}$, Jie Song ${ }^{2}$, Yang Zhou ${ }^{1 *}$ and Xingyu Jiang ${ }^{1 *}$

\begin{abstract}
Background: $\mathrm{Na}^{+}$extrusion from cells is important for plant growth in high saline environments. SOS1 (salt overly sensitive 1), an $\mathrm{Na}^{+} / \mathrm{H}^{+}$antiporter located in the plasma membrane (PM), functions in toxic $\mathrm{Na}^{+}$extrusion from cells using energy from an electrochemical proton gradient produced by a PM-localized $\mathrm{H}^{+}$-ATPase (AHA). Therefore, SOS1 and AHA are involved in plant adaption to salt stress.

Results: In this study, the genes encoding SOS1 and AHA from the halophyte Sesuvium portulacastrum (SpSOS1 and SPAHA1, respectively) were introduced together or singly into Arabidopsis plants. The results indicated that either SpSOS1 or SpAHA1 conferred salt tolerance to transgenic plants and, as expected, Arabidopsis plants expressing both SpSOS1 and SPAHA1 grew better under salt stress than plants expressing only SpSOS1 or SpAHA1. In response to NaCl treatment, $\mathrm{Na}^{+}$and $\mathrm{H}^{+}$in the roots of plants transformed with SpSOS1 or SpAHA1 effluxed faster than wild-type (WT) plant roots. Furthermore, roots co-expressing SpSOS1 and SpAHA1 had higher $\mathrm{Na}^{+}$and $\mathrm{H}^{+}$efflux rates than single SpSOS1/SpAHA1-expressing transgenic plants, resulting in the former amassing less $\mathrm{Na}^{+}$than the latter. As seen from comparative analyses of plants exposed to salinity stress, the malondialdehyde (MDA) content was lowest in the cotransgenic SpSOS1 and SPAHA1 plants, but the $\mathrm{K}^{+}$level was the highest.
\end{abstract}

Conclusion: These results suggest SpSOS1 and SPAHA1 coordinate to alleviate salt toxicity by increasing the efficiency of $\mathrm{Na}^{+}$extrusion to maintain $\mathrm{K}^{+}$homeostasis and protect the PM from oxidative damage induced by salt stress.

Keywords: $\mathrm{H}^{+}$-ATPase, $\mathrm{Na}^{+} / \mathrm{H}^{+}$antiporter, Plasma membrane, Salt tolerance, Sesuvium portulacastrum

\section{Background}

Salts, particularly $\mathrm{NaCl}$, can be toxic to plants through inhibition of important biochemical and physiological processes, such as protein synthesis, photosynthesis, and enzymatic reactions, after moving into the cytosol from soils [1]. While salt stress can inhibit plant growth and development, many types of plants are able to grow in high salinity environments because they have complex mechanisms that facilitate adaptation to salinity stress [2]. Of these mechanisms, the ability to transport excess $\mathrm{Na}^{+}$out of cells is critical to salt tolerance. SOS1 (salt overly sensitive 1 ) is a $\mathrm{Na}^{+} / \mathrm{H}^{+}$antiporter and the only

\footnotetext{
*Correspondence: zhouyang@hainu.edu.cn; jiangxingyuhu@163.com ${ }^{\dagger}$ Yafei Fan and Xiaochang Yin contributed equally to this work.

${ }^{1}$ Hainan Key Laboratory for Sustainable Utilization of Tropical Bioresources /Institute of Tropical Agriculture and Forestry, Hainan University, Haikou 570228, China

Full list of author information is available at the end of the article
}

$\mathrm{Na}^{+}$efflux protein present in plant plasma membranes (PMs) characterized to date. SOS1 mediates extrusion of $\mathrm{Na}^{+}$through a proton gradient generated by the $\mathrm{H}^{+}$-ATPase (AHA) in the PM [3]. Therefore, SOS1 and AHA are two key plant halotolerance factors.

PM $\mathrm{H}^{+}$-ATPase is encoded by a large family of genes $[4,5]$. Bioinformatics analyses of Arabidopsis and genomic sequences of rice revealed the presence of 11 and 10 PM AHAs, respectively [6, 7]. Of these AHAs, $\mathrm{NaCl}$ treatment induced expression of three, AtAHA1, AtAHA2, and AtAHA3, in Arabidopsis [8]. The transcript levels of PM AHA were found to be higher in a salt-tolerant poplar than a salt-sensitive poplar [9]. In addition, PM AHA mRNA is more abundant in halophytes than glycophytes $[10,11]$. Salinity causes upregulation of PM $A H A$ gene expression, as well as accelerates protein biosynthesis and $\mathrm{H}^{+}$-pumping activity in some plants [12-14]. AHA in a salt-tolerant rice species has higher activity than in a

(c) The Author(s). 2019 Open Access This article is distributed under the terms of the Creative Commons Attribution 4.0 International License (http://creativecommons.org/licenses/by/4.0/), which permits unrestricted use, distribution, and 
salt-sensitive rice species [15]. An Arabidopsis PM AHA4 mutant has dramatically reduced growth when exposed to salt stress compared to WT [16]. Expression of a constitutively activated PM AHA lacking the autoinhibitory domain in transgenic tobacco plants increases salt tolerance compared to untransformed plants [17].

SOS1 genes have been found in many plants [18-25]. Of these, Arabidopsis SOS1 (AtSOS1) was the first PM $\mathrm{Na}^{+} / \mathrm{H}^{+}$antiporter to be thoroughly physiologically, biochemically, and molecularly characterized $[18,26]$. Exposure to salinity stress increases SOS1 transcript abundance in wheat plants [19], induces the accumulation of SOS1 mRNA in rice plants [27], and causes upregulation of SOS1 transcription in Arabidopsis [28]. Under high salt conditions, SOS1 mRNA levels are higher in Thellungiella salsuginea (a halophytic Arabidopsis-relative plant) than Arabidopsis [20]. Mutant Arabidopsis plants lacking SOS1 are extremely sensitive to salt stress $[18,29]$. Thellungiella salsuginea lines expressing SOS1-RNAi (RNA interference) are sensitive to salt [20]. The salt sensitivity of an Arabidopsis sos $1 \mathrm{mu}-$ tant can be overcome by transforming in native or other plant SOS1 genes [27, 28]. Arabidopsis overexpressing AtSOS1 is more salt tolerant than WT plants [30]. Expression of wheat SOS1 (TaSOS1) in transgenic tobacco plants improves their growth following $\mathrm{NaCl}$ treatment [31]. SOS1 uses the proton gradient established by PM AHA to exchange $\mathrm{Na}^{+}$for $\mathrm{H}^{+}$across the PM $[3,27]$. The aforementioned data indicate the $\mathrm{PM} \mathrm{Na} \mathrm{Na}^{+} / \mathrm{H}^{+}$antiporter SOS1 and $\mathrm{H}^{+}$-ATPase AHA are involved in plant salt tolerance, where an $\mathrm{Na}^{+} / \mathrm{H}^{+}$antiporter utilizes the proton gradient generated by $\mathrm{H}^{+}$-ATPase to move $\mathrm{Na}^{+}$from the cytoplasm to the external medium and help plant cells maintain non-toxic cytosolic concentrations of $\mathrm{Na}^{+}$. Therefore, theoretically, coordinating SOS1 and AHA could enhance $\mathrm{Na}^{+}$extrusion, where co-expression of these two genes should confer better tolerance to salinity to transgenic plants. However, it has not been reported whether SOS1 and AHA1 function cooperatively in transgenic plants to more efficiently improve salinity tolerance.

Sesuvium portulacastrum is a halophyte that grows optimally in the presence of $200-300 \mathrm{mM} \mathrm{NaCl}$ [32]. When growing in a saline environment, S. portulacastrum cells accumulate large amounts of $\mathrm{Na}^{+}$despite salt glands and bladders not being present in all tissues [33-35], suggesting $S$. portulacastrum may have a unique ability to remove $\mathrm{Na}^{+}$from cells. The SOS1 protein functions as a $\mathrm{PM} \mathrm{Na}^{+} / \mathrm{H}^{+}$antiporter driven by the proton gradient that is produced by the PM $\mathrm{H}^{+}$-ATPase AHA, so they are considered as superior salt tolerance determinants $[3,36]$. The SpAHA1 and SpSOS1 genes encode a $\mathrm{PM} \mathrm{H}^{+}$-ATPase and $\mathrm{Na}^{+} / \mathrm{H}^{+}$antiporter, respectively, and are more highly transcribed in $S$. portulacastrum plants exposed to salt stress. SpSOS1 more efficiently mediates $\mathrm{Na}^{+}$removal using a proton gradient created by SpAHA1 in $S p A$ HA1-SpSOS1 co-transgenic yeast cells, where yeast cells co-expressing SpSOS1 and SpAHA1 grow better following $\mathrm{NaCl}$ treatment than cells transformed with only SpSOS1 or SpAHA1 [3]. Over-expression of SpAHA1 conferred salt tolerance to transgenic Arabidopsis [37]. SpSOS1 complemented the salt sensitivity of transgenic Arabidopsis sos 1 mutant plants [38]. These results suggest that SpSOS1 and SpAHA1 are involved in salt tolerance of $S$. portulacastrum, and co-expression of SpAHA1 and SpSOS1 may improve transgenic plant salt tolerance. To test this hypothesis, SpAHA1 and SpSOS1 genes were co-transformed into Arabidopsis plants. Functional analyses indicate that Arabidopsis plants co-expressing SpSOS1 and SpAHA1 had better salt tolerance than plants expressing either gene alone due to efficient $\mathrm{Na}^{+}$removal mediated by SpSOS1 using the extra proton gradient generated by SpAHA1. Therefore, genetic evidence may significantly guide development of more salt tolerant crops using PM-localized $\mathrm{Na}^{+} / \mathrm{H}^{+}$antiporters and $\mathrm{H}^{+}$-ATPases.

\section{Results}

Transgenic plant identification

SpSOS1 and SpAHA1 were transformed alone or together into Arabidopsis plants using Agrobacteria carrying pCAMBIA1304-SpSOS1, pCAMBIA1304-SpAHA1, or pCAMBIA1304-SpSOS1-SpAHA1. PCR analyses of genomic DNA performed using SpAHA1/SpSOS1 and hygB gene-specific primers revealed 12 SpSOS1-, 11 SpAHA1-, and 10 SpSOS1-SpAHA1-transgenic lines were obtained (Additional file 1: Figure S1). Total RNA was isolated from the above transgenic plant lines and RT-PCR analyses were used to study the SpAHA1 and SpSOS1 expression levels. The SpAHA1 gene was significantly expressed in all single SpAHA1-transgenic lines, except for SpAHA1- lines 5 and 8. Of the SpSOS1-expressing single transgenic plants, SpSOS1-line 1 had the highest SpSOS1 expression of the SpSOS1-transgenic lines. In SpAHA-SpSOS1 co-expressing plants, the clearest expression of both SpAHA1 and SpSOS1 was observed in line 10 (Additional file 2: Figure S2). Therefore, the T3 generation transgenic plants of the homozygous SpSOS1-line 1, SpAHA1-line 1, and SpAHA1-SpSOS1-line 10 were used to characterize the functions of SpSOS1 and SpAHA1.

\section{SpSOS1 and SpAHA1 functioned together to more efficiently improve transgenic plant salt tolerance}

In plant cells, the $\mathrm{PM} \mathrm{Na}^{+} / \mathrm{H}^{+}$antiporter SOS1 mediates $\mathrm{Na}^{+}$excretion using a proton gradient created by PM $\mathrm{H}^{+}$- ATPases. Therefore, both of these proteins are involved in plant salt tolerance. Much evidence indicates that overexpressing SOS1 or AHA increases the salt tolerance of transgenic plants [39]. In addition, our recent investigation found SpSOS1 and SpAHA1 function 
cooperatively in transgenic yeast cells, where yeast cells co-expressing SpSOS1 and SpAHA1 are better growers than cells transformed with only SpAHA1 or SpSOS1 [3]. Therefore, we hypothesized co-expression of SpSOS1 and SpAHA1 would increase the salt tolerance of transgenic plants compared to plants transformed with only SpSOS1 or SpAHA1. To examine the influence of SpSOS1-SpAHA1 co-expression on the salt tolerance of transgenic plants, 5-day-old Arabidopsis WT, SpSOS1-expressing, SpAHA1-expressing, and SpSOS1-SpAHA1 co-expressing seedlings were grown on MS plates containing $0,50,75$, or $100 \mathrm{mM} \mathrm{NaCl}$. Two weeks post- $\mathrm{NaCl}$ treatment, the seedlings were photographed and their fresh weight, root length, and lateral root number were measured. Upon exposure to salinity stress, the growth of all tested plants decreased, but expression of either SpSOS1 or SpAHA1 ameliorated this growth inhibition from $\mathrm{NaCl}$ treatment compared to WT plants. Furthermore, among all the transgenic plants, salt tolerance improved the most in plants co-expressing SpSOS1 and SpAHA1 based on growth in MS medium containing different concentrations of $\mathrm{NaCl}$ (Fig. 1).

Similarly, the growth of transgenic and WT plants was inhibited in soil supplemented with $200 \mathrm{mM} \mathrm{NaCl}$. However, Arabidopsis plants expressing both SpSOS1 and SpAHA1 grew the best among the different experimental cohorts under these conditions (Fig. 2a). SpAHA1-SpSOS1-line 10 displayed 26, 33, and 67\% greater fresh weights than SpSOS1-line 1, SpAHA1-line 1, and WT plants, respectively (Fig. 2b). The percent reduction in growth of plant lines treated with $\mathrm{NaCl}$ was ordered: SpSOS1-SpAHA1 co-expressing plants $<$ SpSOS1-expressing plants $<$ SpAHA1-expressing plants $<$ WT plants (Fig. 2c). These findings indicate the PM-localized $\mathrm{Na}^{+} / \mathrm{H}^{+}$antiporter SpSOS1 and $\mathrm{H}^{+}$-AT Pase SpAHA1 function cooperatively to improve the salt tolerance of transgenic plants.
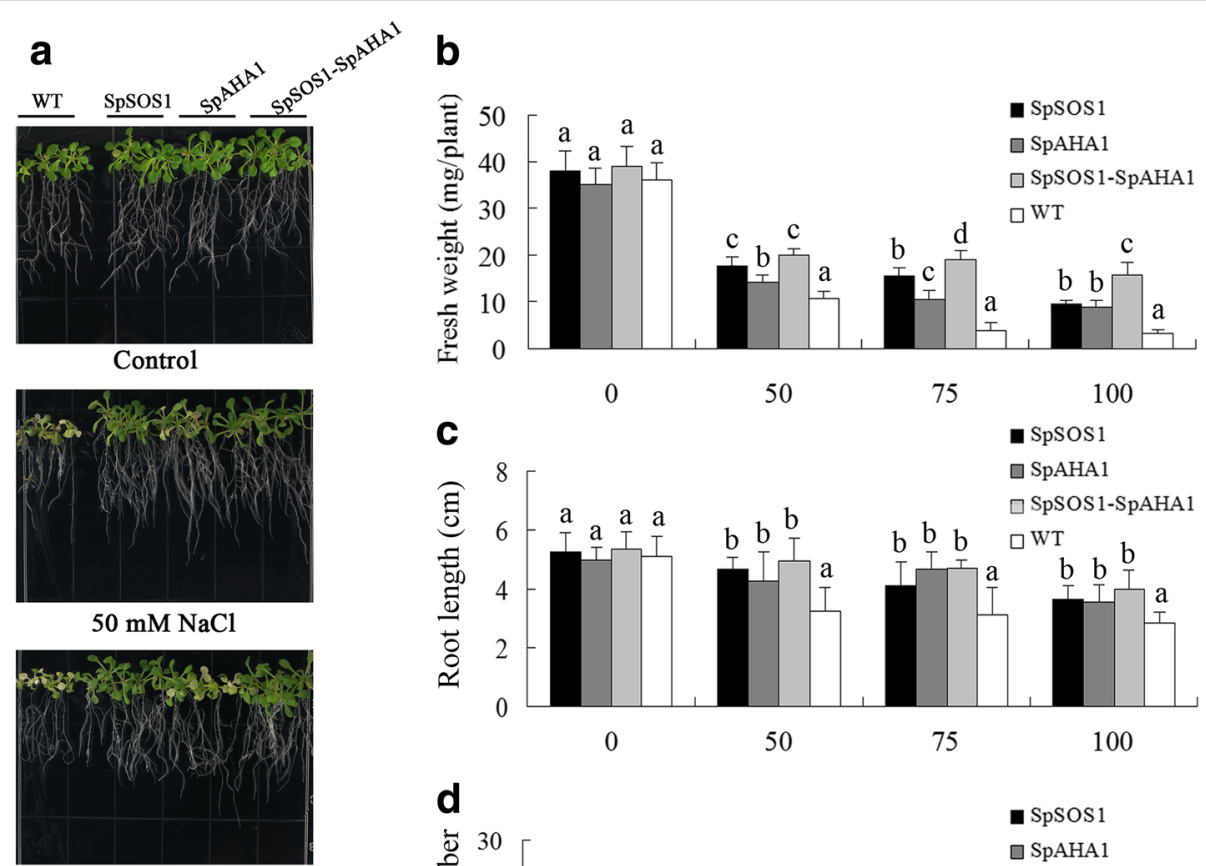

100

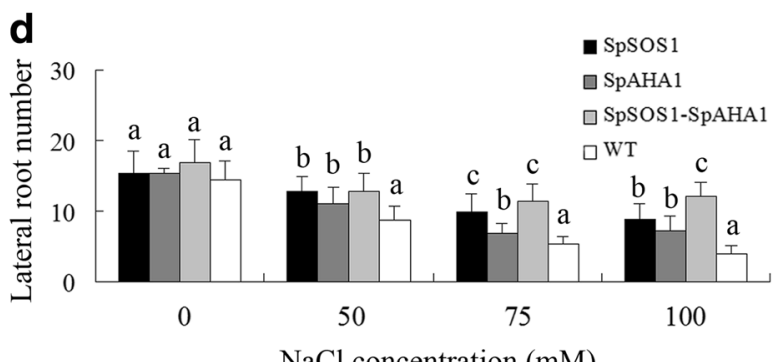

Fig. 1 Growth of transgenic and WT seedlings under salt stress. Five-day-old seedlings grown on MS plates were transferred to MS plates containing 0 , 50, 75, and $100 \mathrm{mM} \mathrm{NaCl}$. a The seedlings were photographed after 2 weeks of growth. The growth was assessed based on fresh weight (b), root length (c), and number of lateral roots (d). Data are presented as mean \pm SE of 12 replicates, where the different letters above the columns indicate statistically significant differences at a $p<0.05$ level between the experimental cohorts. SpSOS1, SpSOS1-overexpressing plants; SpAHA1, SpAHA1-overexpressing plants; SpSOS1-SPAHA1, SPSOS1 and SPAHA1 co-expressing plants; WT, wild-type plants 


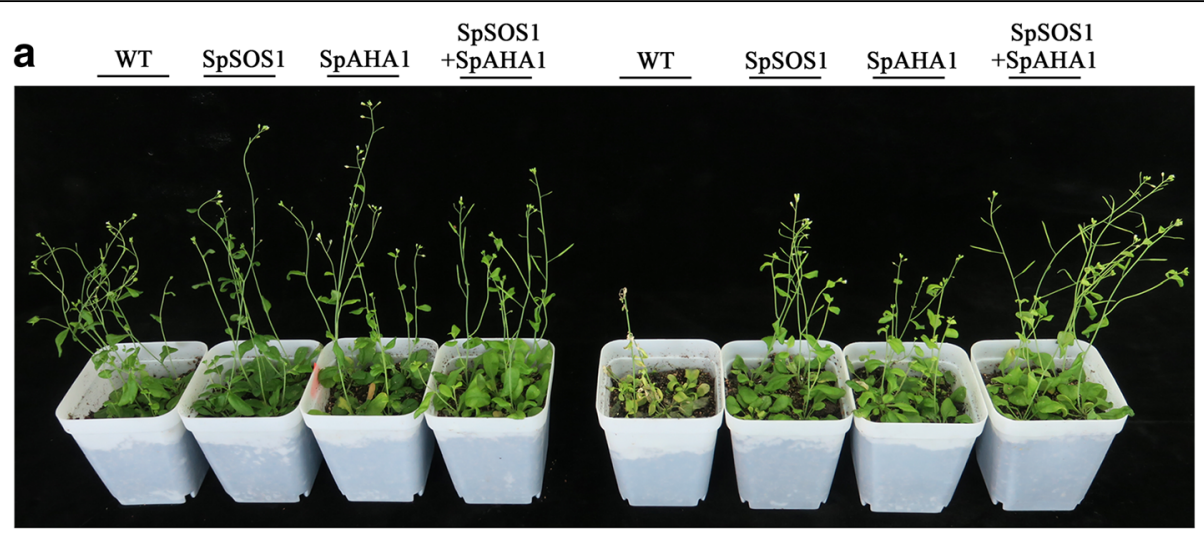

Control

$200 \mathrm{mM} \mathrm{NaCl}$
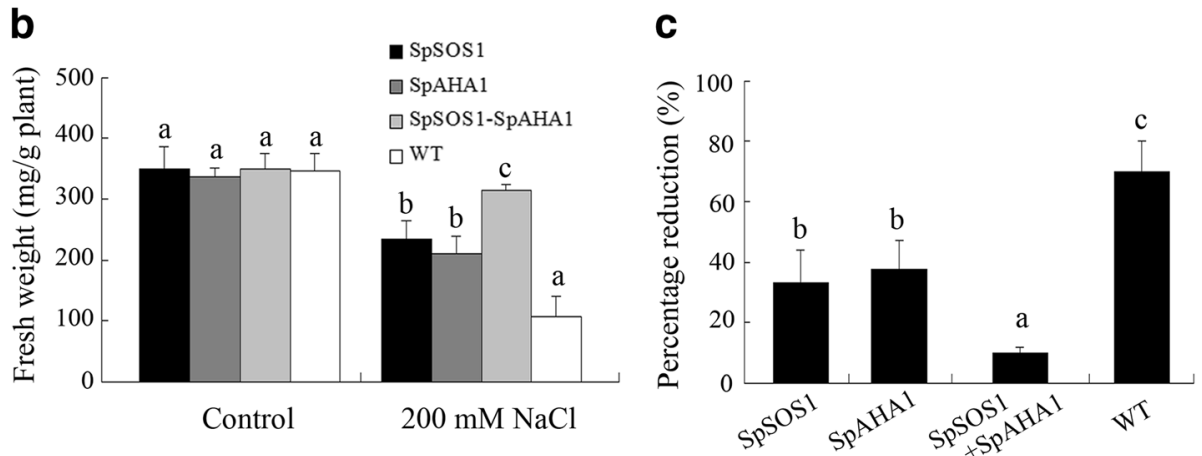

Fig. 2 Growth of transgenic and WT seedlings. Seven-day-old WT and transgenic seedlings were transferred from MS plates into soil (4 plants/ pot) grown for 4 weeks. The plants were then treated with 0 or $200 \mathrm{mM} \mathrm{NaCl}$. Ten days post-treatment, the plants were photographed (a) and their fresh weight was measured (b). The two preparations were performed at different times to more accurately assess the salt tolerance of the transgenic plants and (c) the relative change (percentage reduction) in fresh weight in the presence of salt stress relative to the nonstressed control was determined. Data are presented as mean \pm SE of nine replicates. Different letters above the columns indicate statistically significant differences at a $p<0.05$ level among the different experimental cohorts. SpSOS1, SpSOS1-overexpressing plants; SpAHA1, SpAHA1-overexpressing plants; SpSOS1 + SPAHA1, SpSOS1 and SpAHA1 co-expressing plants; WT, wild-type plants

\section{SpSOS1-SpAHA1 co-expressing Arabidopsis plants had} higher $\mathrm{H}^{+}$efflux rates than SpSOS1- or SpAHA1-expressing plants under high saline conditions

Net $\mathrm{H}^{+}$flux at the roots of WT plants was close to the mock control (Fig. 3A), which is in full agreement with the recent report that both transient and long-term salinity exposure did not induce $\mathrm{H}^{+}$efflux from Arabidopsis roots [8]. These results suggested that $\mathrm{H}^{+}$efflux might be balanced by $\mathrm{H}^{+}$influx at the roots exposed to salinity stress. PM $\mathrm{H}^{+}$-ATPase activity is a major factor in $\mathrm{H}^{+}$excretion at the PM [40]. It was recently reported that SpAHA1 can function as an $\mathrm{H}^{+}$-ATPase on vesicles isolated from yeast cells expressing $S p A H A 1$ [3]. Roots expressing SpAHA1 had a faster net $\mathrm{H}^{+}$efflux than the WT plants under saline conditions, suggesting SpAHA1 is responsible for the extra $\mathrm{H}^{+}$efflux, i.e., SpAHA1 pumped more protons out of the cells. It is not expected that protons were extruded faster in roots transformed with SpSOS1 relative to WT plants and the phenomenon might be from feedback regulation of $\mathrm{Na}^{+}$extrusion mediated by SpSOS1. This hypothesis is also supported by the
$\mathrm{H}^{+}$flux in the roots of SpSOS1-SpAHA1 co-expressing transgenic plants (Fig. 3) being the highest among all the transgenic plants, where the $\mathrm{H}^{+}$efflux rates in the roots co-expressing SpSOS1-SpAHA1 were 49 and 52\% greater than SpSOS1- and SpAHA1-expressing roots, respectively.

\section{Plants co-expressing SpSOS1-SpAHA1 had higher $\mathrm{Na}^{+}$ efflux in roots and less $\mathrm{Na}^{+}$accumulation after $\mathrm{NaCl}$ treatment}

SOS1 mediates $\mathrm{Na}^{+}$excretion from cells and is a key halotolerance factor. SpSOS1 has been shown to be a PM-localized $\mathrm{Na}^{+} / \mathrm{H}^{+}$antiporter and capable of improving the growth of transgenic yeast cells under salt stress by decreasing the cellular $\mathrm{Na}^{+}$content [3]. In this scenario, the roots from all tested plants grown in medium without $\mathrm{NaCl}$ displayed $\mathrm{Na}^{+}$uptake characteristics, but no significant differences in $\mathrm{Na}^{+}$flux activities at roots of transgenic and untransformed plants under unstressed condition were observed (Additional file 3: Figure S3). On the contrary, $\mathrm{NaCl}$ treatment stimulated $\mathrm{Na}^{+}$effluxes at all tested roots. SpSOS1-expressing roots had faster $\mathrm{Na}^{+}$efflux 


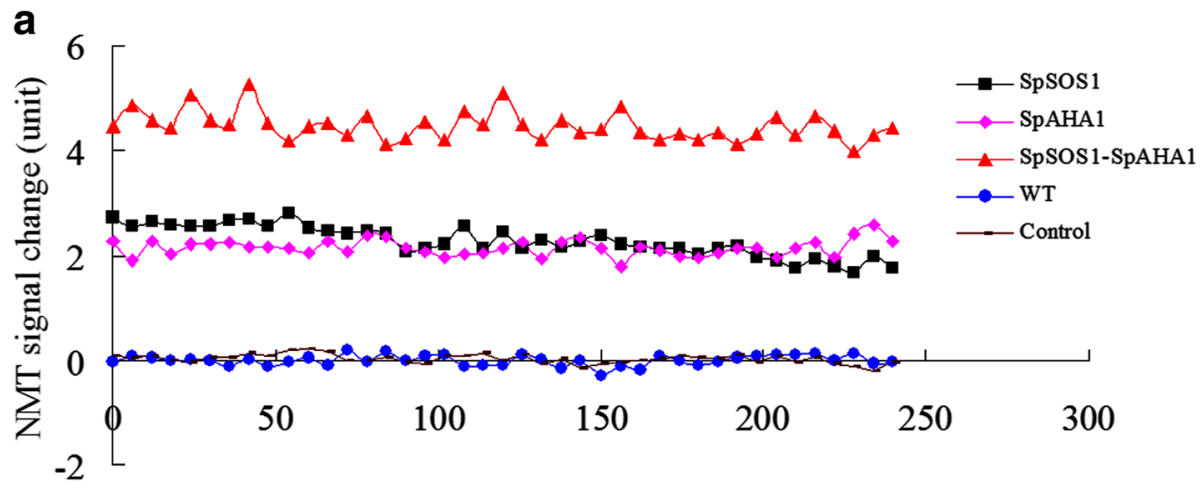

Time (s)

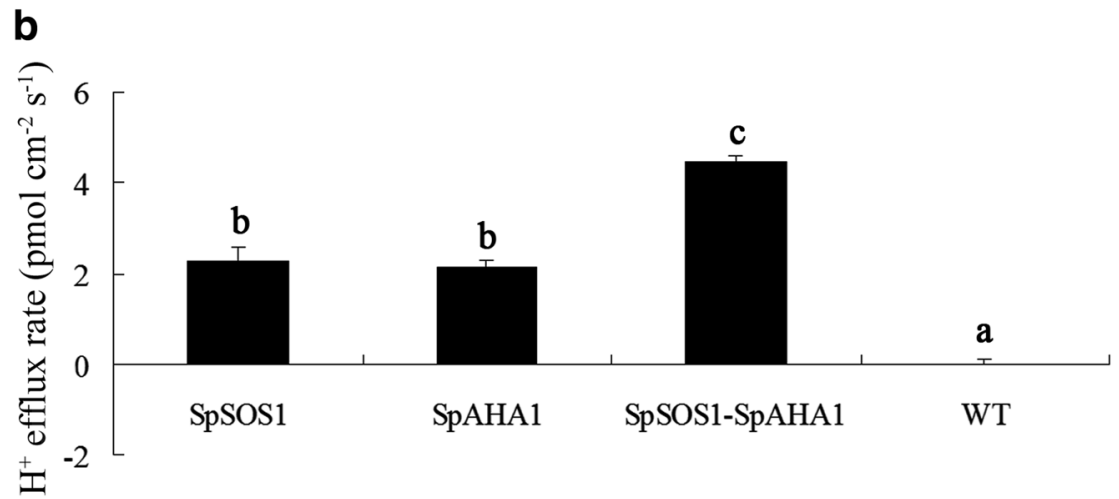

Fig. $3 \mathrm{H}^{+}$flux in roots of $\mathrm{NaCl}$-treated Arabidopsis plants. Seedlings were grown for 3 days on MS plates supplemented with $100 \mathrm{mM} \mathrm{NaCl}$ and then $\mathrm{H}^{+}$flux in the roots was measured using the non-invasive micro-test technology (NMT) technique described in the Methods section. (a) Changes in the NMT signals are expressed as arbitrary units. (b) $\mathrm{H}^{+}$flux is expressed as the amount of efflux per second per square centimeter $\left(\mathrm{pmol} \cdot \mathrm{cm}^{-2} \cdot \mathrm{s}^{-1}\right)$. Data are presented as mean \pm SE of six replicates. Different letters above the columns indicate statistically significant differences at a $p<0.05$ level among the different experimental cohorts. SpSOS1, SpSOS1-overexpressing plants; SpAHA1, SpAHA1-overexpressing plants; SpSOS1-SpAHA1, SpSOS1 and SPAHA1 co-expressing plants; WT, wild-type plants; Control, mock controls

relative to WT plants in saline conditions (Fig. 4a, b), suggesting the extra $\mathrm{Na}^{+}$extrusion may be mediated by SpSOS1, which would result in the observed lower $\mathrm{Na}^{+}$ content in the SpSOS1-transgenic plants than WT plants under salt stress (Fig. 5a). SOS1-mediated $\mathrm{Na}^{+} / \mathrm{H}^{+}$exchange is powered by a proton gradient generated by an $\mathrm{H}^{+}$-ATPase. Therefore, a proton gradient generated by SpAHA1 (Fig. 3) might catalyze native SOS1 (AtSOS1) to transport more $\mathrm{Na}^{+}$out of cells, which may be one reason for the higher $\mathrm{Na}^{+}$efflux rate in roots transformed with SpAHA1 compared to WT plants in saline conditions (Fig. 4). Roots co-expressing SpAHA1 and SpSOS1 had the highest $\mathrm{Na}^{+}$efflux rates among all the transgenic plant lines tested, where the $\mathrm{Na}^{+}$efflux rate in SpSOS1-SpAHA1 co-transgenic roots was 53 and $72 \%$ greater than the plants expressing SpSOS1 or SpAHA1 singly, respectively (Fig. 4b). Correspondingly, the $\mathrm{Na}^{+}$levels in the transgenic plants were lower than in WT plants (Fig. 5a). Therefore, it is reasonable that SpSOS1-SpAHA1 co-expression quickened $\mathrm{Na}^{+}$extrusion in the roots of and decreased $\mathrm{Na}^{+}$accumulation in transgenic plants compared to
SpSOS1- or SpAHA1-expressing plants under saline conditions (Fig. 4, 5a). These results indicate SpAHA1 produced an additional proton gradient and, thus, promoted SpSOS1-mediated $\mathrm{Na}^{+}$extrusion in Arabidopsis plants co-expressing both the SpAHA1 and SpSOS1 genes.

\section{SpSOS1-SpAHA1 co-transgenic plants had higher $\mathrm{K}^{+}$ retention under saline conditions}

Among the physiological and biochemical processes in plant cells influenced by high salinity, nutrient imbalance is among the most deleterious resulting effects [41]. The chemical and physical characteristics of sodium most resemble potassium among the nutrient elements. Therefore, excess $\mathrm{Na}^{+}$inhibits plant growth by interfering with cytosolic $\mathrm{K}^{+}$homeostasis. No differences in $\mathrm{K}^{+}$content was found among all the tested plants under normal conditions. However, upon salinity stress, the transgenic plants displayed less of a decrease in $\mathrm{K}^{+}$content than the WT plants. Furthermore, co-expression of SpSOS1 and SpAHA1 most efficiently alleviated $\mathrm{K}^{+}$loss among the transgenic plants exposed to $\mathrm{NaCl}$, where the $\mathrm{K}^{+}$ 


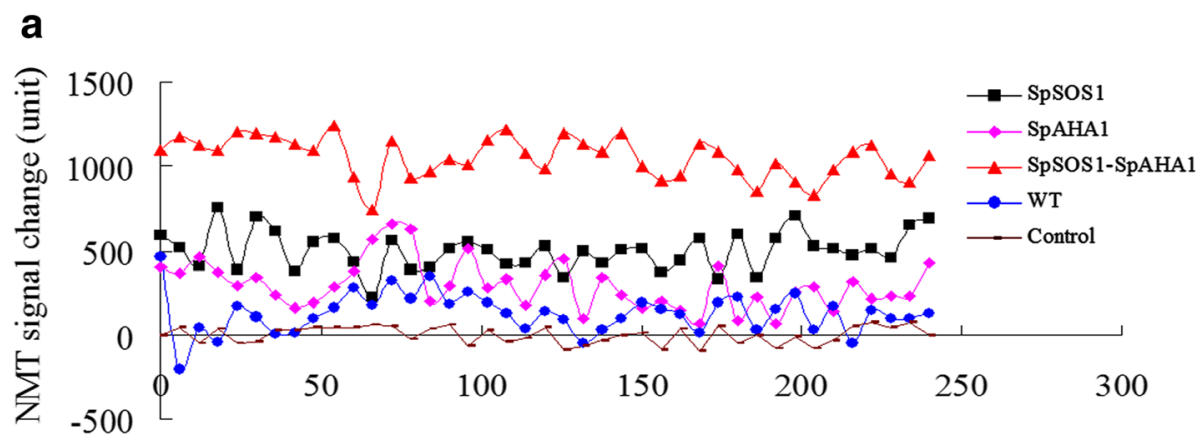

Time (s)

b

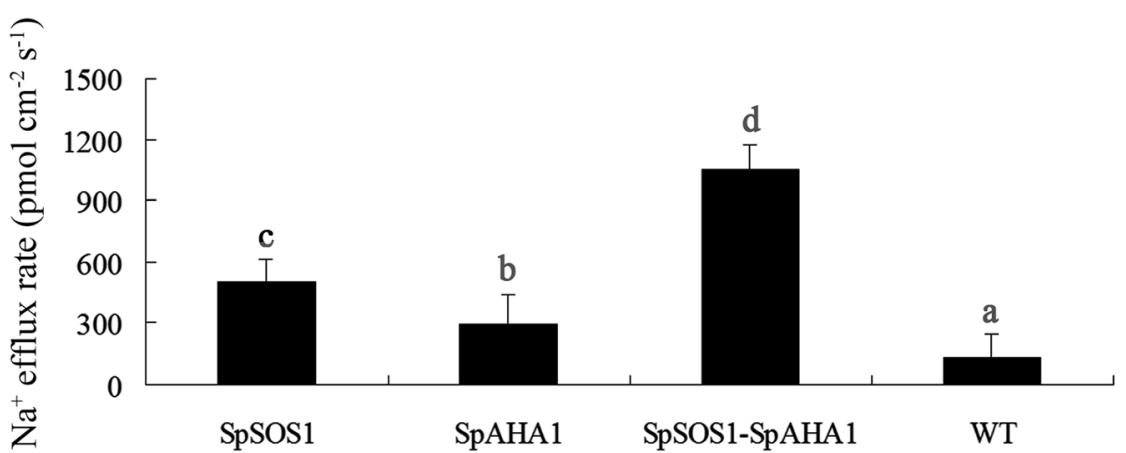

Fig. $4 \mathrm{Na}^{+}$flux in roots of $\mathrm{NaCl}$-treated Arabidopsis plants. Seedlings were grown for 3 days on MS plates containing $100 \mathrm{mM} \mathrm{NaCl} \mathrm{Na}^{+}$flux in the roots was then measured using the NMT technique described in the Methods section. (a) Changes in the NMT signals are expressed as arbitrary units. (b) $\mathrm{Na}^{+}$flux is expressed as the amount of efflux per second per square centimeter $\left(\right.$pmol$\left.\cdot \mathrm{cm}^{-2} \cdot \mathrm{s}^{-1}\right)$. Data are presented as mean $\pm \mathrm{SE}$ of six replicates. Different letters above the columns indicate statistically significant differences at a $p<0.05$ level among the different experimental cohorts. SpSOS1, SpSOS1-overexpressing plants; SpAHA1, SpAHA1-overexpressing plants; SpSOS1-SpAHA1, SpSOS1 and SpAHA1 co-expressing plants; WT, wild-type plants; Control, mock controls

content was highest in the leaves of plants co-expressing SpSOS1 and SpAHA1 (85 mg/g dry weight), followed by those from SpSOS1-transgenic plants $(73 \mathrm{mg} / \mathrm{g}$ dry weight), and then $S p A H A 1$-expressing plants $(69 \mathrm{mg} / \mathrm{g}$ dry weight). WT plants had the lowest $\mathrm{K}^{+}$content $(47 \mathrm{mg} / \mathrm{g}$ dry weight; Fig. 5b).

\section{SpSOS1-SPAHA1 co-expression decreased} malondialdehyde accumulation in transgenic plants

Salinity creates oxidative stress and excess reactive oxygen species can interfere with metabolism in the cytoplasm, such as by damaging membrane structures and destroying membrane integrity through lipid peroxidation [42]. An indicator of membrane lipid oxidation, malondialdehyde (MDA) represents membrane lipid damage to some extent. Upon exposure to $\mathrm{NaCl}$, the amount of MDA in the leaves of all tested plants increased, but MDA accumulation in the SpSOS1-SpAHA1 co-expressing leaves was the lowest (Fig. 6) at only 84, 74 , and $61 \%$ of that in SpSOS1-expressing, SpAHA1-expressing, and WT plants under saline conditions. These results indicate $S p S O S 1$ and SpAHA1 coordination could more efficiently reduce oxidative damage to membranes from salinity stress in transgenic plants.

\section{Discussion}

Plants grown under $\mathrm{K}^{+}$deficiency substitute it by $\mathrm{Na}^{+}$, especially some halophyte species can use $\mathrm{Na}^{+}$for stomata operation instead of $\mathrm{K}^{+}$[43]. However, when there is excess sodium in the cytosol, it interferes with some key metabolic processes and eventually inhibits the growth and development of the plant. To tolerate high $\mathrm{Na}^{+}$levels, plant cells must be capable of removing $\mathrm{Na}^{+}$ from the cytoplasm through some physiological processes. In one of these processes, cytoplasmic $\mathrm{Na}^{+}$can be imported into vacuoles through tonoplast $\mathrm{Na}^{+} / \mathrm{H}^{+}$ antiporter NHXs using an electrochemical gradient established by a vacuolar $\mathrm{H}^{+}$-ATPase and $\mathrm{H}^{+}$-PPase (AVP/VP) using protons. The sequestration of $\mathrm{Na}^{+}$into vacuoles not only prevents the deleterious effects resulting from $\mathrm{Na}^{+}$in the cytoplasm, but also lets the plants use $\mathrm{Na}^{+}$as an osmoticum, which helps maintain the osmotic potential that drives water into the cells [39, 44]. Therefore, tonoplast NHX antiporters and $\mathrm{H}^{+}$-pumps 

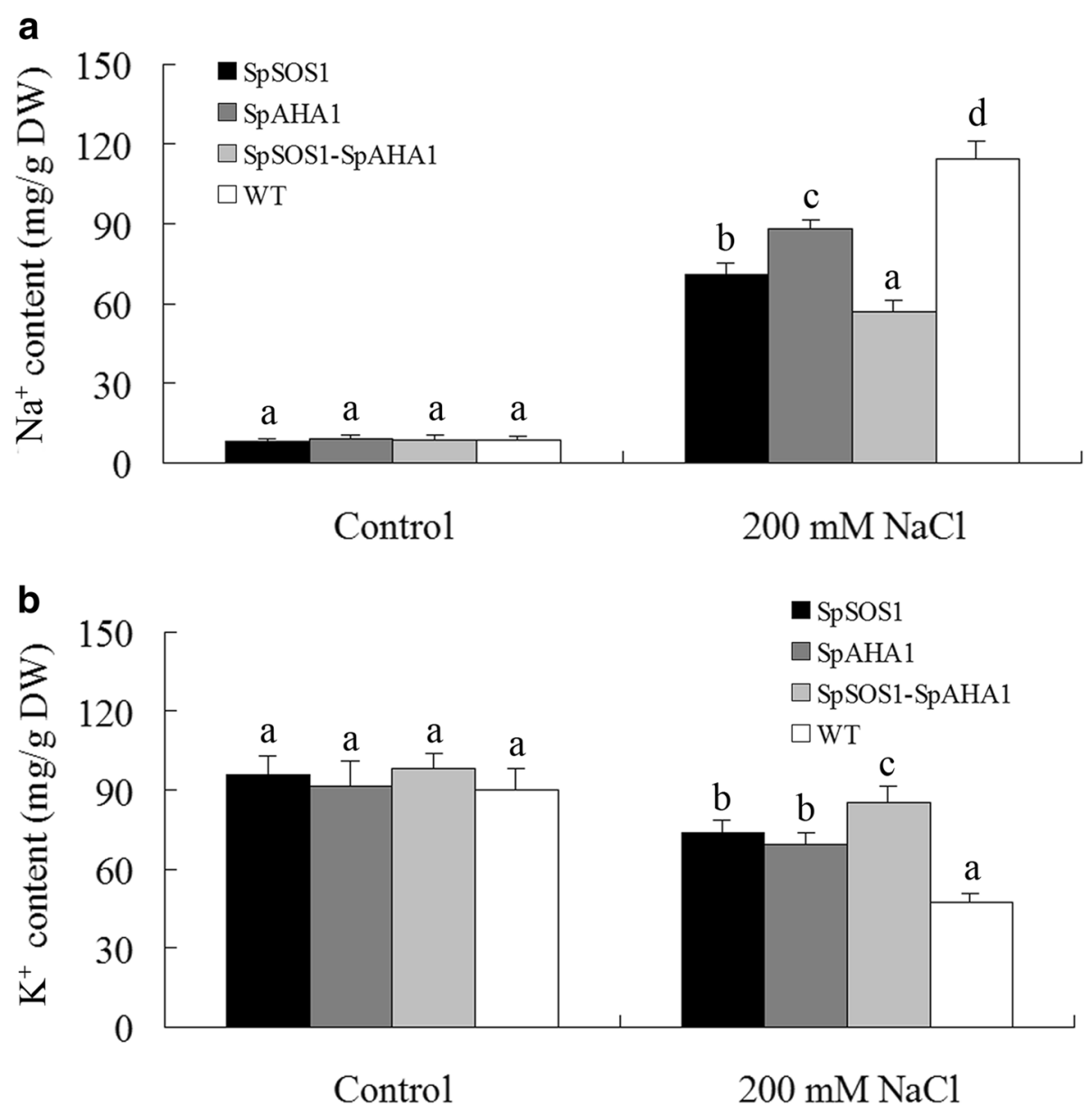

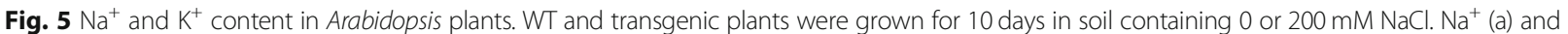
$\mathrm{K}^{+}(\mathrm{b})$ in the leaves of these plants were measured as described in the Methods section. Data are presented as mean \pm SE of three replicates. Different letters above the columns indicate statistically significant differences at a $p<0.05$ level among the different experimental cohorts. SpSOS1, SpSOS1overexpressing plants; SpAHA1, SpAHA1-overexpressing plants; SpSOS1-SpAHA1, SpSOS1 and SpAHA1 co-expressing plants; WT, wild-type plants

have important functions in plant responses to salt stress. In transgenic plants, overexpression of genes encoding vacuolar $\mathrm{Na}^{+} / \mathrm{H}^{+}$antiporters or $\mathrm{H}^{+}$-PPases enhances salt tolerance [39, 42]. Furthermore, co-expression of AVP and NHX may better improve the growth of transgenic plants exposed to salt stress through more efficient compartmentalization of $\mathrm{Na}^{+}$into vacuoles than when NHX or AVP are expressed alone. Co-expression of $Z x N H X$ and $Z x V P 1-1$ confers better salt tolerance to transformed sugar beet and lotus plants [42, 45]. NHX1-AVP1 co-transgenic rice grows better under salt stress than rice plants expressing only one of these genes $[46,47]$. Tobacco plants co-expressing TNHXS1 and TVP1 have higher salt tolerance than transgenic plants expressing TNHXS1 or TVP1 alone [48]. Another mechanism contributing to $\mathrm{Na}^{+}$extrusion is the $\mathrm{PM} \mathrm{Na} \mathrm{Na}^{+} / \mathrm{H}^{+}$ antiporter SOS1. The $\mathrm{Na}^{+}$extrusion mediated by SOS1 is also driven by electrochemical gradients of protons generated by a PM $\mathrm{H}^{+}$-pump $\left(\mathrm{H}^{+}\right.$-ATPase, AHA). The overexpression of SOS1 significantly improves the salt tolerance of transgenic grapevine compared to WT plants [49]. Overexpression of the SOS1 gene in tobacco plants increases salt tolerance by maintaining a lower $\mathrm{Na}^{+}$content [50] and the growth of Arabidopsis plants overexpressing SOS1 is better than that of WT plants under salt stress [51]. It has been reported that overexpression of PeHA1 $\left(\mathrm{H}^{+}\right.$-ATPase 1), a poplar gene encoding a PM-localized $\mathrm{H}^{+}$-ATPase, enhances the salt tolerance of transgenic Arabidopsis [52]. These studies suggest that co-expression of both $S O S 1$ and $A H A$ in transgenic plants should more effectively increase salinity tolerance just as co-expression of vacuolar NHX and AVP results in higher salt tolerance. In the present investigation, SpAHA1-transgenic roots had faster $\mathrm{H}^{+}$efflux than WT plants under salt stress (Fig. 3), suggesting SpAHA1 enhanced proton efflux and generated an additional proton gradient that acted as a driving force for $\mathrm{Na}^{+} / \mathrm{H}^{+}$exchange mediated by SpSOS1 . More interestingly, the magnitude of net $\mathrm{H}^{+}$flux is in 3 to 


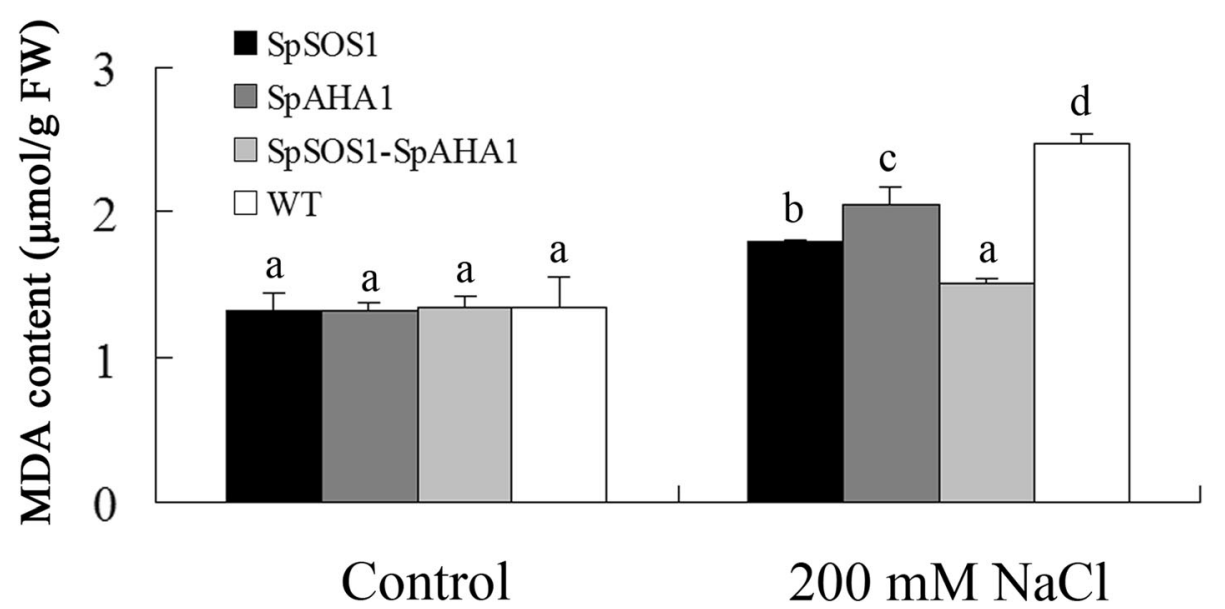

Fig. 6 Malondialdehyde content in leaves. Two-week-old WT and transgenic Arabidopsis seedlings were treated with $200 \mathrm{mM} \mathrm{NaCl}$ for 7 days and then their leaves were harvested. Malondialdehyde content in the leaves was measured as described in the Methods section. Data are presented as mean \pm SE of three replicates. Different letters above the columns indicate statistically significant differences at a $p<0.05$ level among the different experimental cohorts. SpSOS1, SpSOS1-overexpressing plants; SpAHA1, SpAHA1-overexpressing plants; SpSOS1-SpAHA1, SpSOS1 and SPAHA1 Co-expressing plants; WT, wild-type plants

4 pmol $\bullet \mathrm{cm}^{-2} \cdot \mathrm{s}^{-1}$ range (Fig. 3), while $\mathrm{Na}^{+}$flux is around $1000 \mathrm{pmol} \cdot \mathrm{cm}^{-2} \cdot \mathrm{s}^{-1}$; the stoichiometric ratio for $\mathrm{Na}^{+} / \mathrm{H}^{+}$ exchange of SOS1 protein is $1 \mathrm{H}^{+}: 1 \mathrm{Na}^{+}$, so such tiny increase in $\mathrm{H}^{+}$flux (from 2 to $4 \mathrm{pmol} \cdot \mathrm{cm}^{-2} \cdot \mathrm{s}^{-1}$ ) may not cause such a massive flux of $\mathrm{Na}^{+}$. Net $\mathrm{H}^{+}$fluxes at roots was determined in the present study, that is, the data for net $\mathrm{H}^{+}$efflux is equal to total $\mathrm{H}^{+}$efflux minus total $\mathrm{H}^{+}$influx at the roots, suggesting that $\mathrm{H}^{+}$-ATPase mediated $\mathrm{H}^{+}$ efflux is likely balanced by $\mathrm{H}^{+}$uptake through SOS1 transporters. These suggest that SpAHA1 might provided more $\mathrm{H}^{+}$gradient than the shown data of net $\mathrm{H}^{+}$efflux in transgenic plant exposed to salinity stress, resulting in faster $\mathrm{Na}^{+}$efflux from cells, consequently $\mathrm{Na}^{+}$content in transgenic plants was lower than that in wild type plants (Fig. 5a). Overexpression of SpSOS1 in transgenic Arabidopsis accelerated $\mathrm{Na}^{+}$efflux in the roots (Fig. 4a, b), resulting in decreased $\mathrm{Na}^{+}$content in the transgenic plants compared to the WT plants (Fig. 5a). Interestingly, the rate of $\mathrm{H}^{+}$efflux in the SpSOS1-expressing roots was faster than in the WT or SpAHA1-transgenic roots (Fig. 3), suggesting that increased $\mathrm{Na}^{+}$extrusion mediated by SpSOS1 might regulate $\mathrm{H}^{+}$-pumping activity via feedback at the PM. This is because the $\mathrm{Na}^{+} / \mathrm{H}^{+}$exchange mediated by SOS1 is dependent on energy and driven using a PM-localized $\mathrm{H}^{+}$-ATPase-driven proton motive force [53]. The $\mathrm{H}^{+}$and $\mathrm{Na}^{+}$efflux rates in the roots of Arabidopsis plants co-expressing SpAHA1 and SpSOS1 were highest among all the transgenic plants (Figs. 3 and 4), leading to the lowest $\mathrm{Na}^{+}$content in the co-transformed plants relative to other transgenic plants expressing only SpSOS1 or SpAHA1 (Fig. 5a). In response to $\mathrm{NaCl}$ treatment, the biomass of the transgenic Arabidopsis plants co-expressing SpSOS1 and SpAHA1 was greater than the biomasses of the single-gene expressing plants (Fig. 2). Taken together, the higher rate of $\mathrm{Na}^{+}$extrusion, lower $\mathrm{Na}^{+}$levels, and better growth of the SpAHA1-SpSOS1 co-expressing plants compared to the single SpAHA1 or SpSOS1 gene transgenic plants provides direct genetic evidence that SOS1 and AHA function in a cooperative manner to inhibit $\mathrm{Na}^{+}$accumulation in the cytosol and play important roles in plant adaption to highly saline conditions.

High soil salinity is characterized by high soluble salt concentrations, of which sodium salt is the most soluble and widespread salt [44]. Excessive sodium ions in soils can enter into plant cells and then interference with some critical biochemical and physiological processes. The most deleterious effect of salinity is ion toxicity [41]. $\mathrm{K}^{+}$is a necessary macronutrient that has a critical role in the growth and development of plants [54]. Due physicochemical similarities between $\mathrm{Na}^{+}$and $\mathrm{K}^{+}, \mathrm{Na}^{+}$ can compete with $\mathrm{K}^{+}$for binding sites important in critical cytoplasmic physiological and biochemical processes [55]. In particular, $\mathrm{Na}^{+}$inhibits the activity of many $\mathrm{K}^{+}$-dependent enzymes [56] and, therefore, excess $\mathrm{Na}^{+}$ can inhibit $\mathrm{K}^{+}$-associated activities in the cytosol [55]. It is hypothesized that plant survival in the presence of salt stress requires a high $\mathrm{K}^{+} / \mathrm{Na}^{+}$ratio in the cytoplasm [57]. Therefore, limiting $\mathrm{Na}^{+}$influx into cells may facilitate plant growth under salt stress $[58,59]$. Under high salt conditions, the PM potential becomes depolarized, which encourages passive $\mathrm{Na}^{+}$influx into cells and $\mathrm{K}^{+}$ efflux out of cells. $\mathrm{H}^{+}$-ATPase-generated electrochemical potential gradients across PMs can repolarize PMs following $\mathrm{NaCl}$-induced depolarization [39]. Therefore, maintenance of the PM potential using $\mathrm{H}^{+}$-ATPases can reduce the $\mathrm{Na}^{+}$influx via depolarization-activated 
non-selective cation channels (NSCCs) and $\mathrm{K}^{+}$efflux via $\mathrm{K}^{+}$outward rectifiers (KORs) and NSCCs [60]. The net $\mathrm{H}^{+}$efflux from root cells in SpAHA1-transgenic plants occurred at a higher rate relative to WT plant roots, suggesting SpAHA1 increased the $\mathrm{H}^{+}$-ATPase activity and electrochemical potential and, thus, the $\mathrm{H}^{+}$gradient across the PM. This may reduce $\mathrm{Na}^{+}$influx and $\mathrm{K}^{+}$efflux and, correspondingly, the SpAHA1-transgenic plants had less $\mathrm{Na}^{+}$and more $\mathrm{K}^{+}$than WT plants (Fig. 5a, b). In addition to $\mathrm{Na}^{+}$extrusion, SOS1 is also involved in $\mathrm{K}^{+}$homeostasis in plant cells under high salt conditions. Transgenic tobacco plants expressing SbSOS1 contain less $\mathrm{Na}^{+}$, but more $\mathrm{K}^{+}$, in their roots than WT plants under high salt stress [50]. Horie et al. [61] suggested SOS1 plays a primary role facilitating high-affinity absorption of $\mathrm{K}^{+}$into roots. SOS1 is necessary for protecting $\mathrm{K}^{+}$uptake and is involved in $\mathrm{K}^{+}$homeostasis maintenance in cells under salinity stress $[19,62]$. Overexpression of TaSOS1 confers salt tolerance to transgenic tobacco plants by decreasing the $\mathrm{Na}^{+}$and increasing the $\mathrm{K}^{+}$ levels [31]. Arabidopsis roots expressing SpSOS1 displayed faster $\mathrm{Na}^{+}$efflux than WT plant roots under saline condition (Fig. 4), suggesting SpSOS1 was responsible for the extra $\mathrm{Na}^{+}$extrusion. The faster $\mathrm{H}^{+}$efflux in the roots of plants expressing SpSOS1 may aid repolarization following $\mathrm{NaCl}$-induced depolarization of the PM, thus decreasing $\mathrm{Na}^{+}$influx and $\mathrm{K}^{+}$efflux [60]. These actions may have led SpSOS1-transgenic plants to contain less $\mathrm{Na}^{+}$and more $\mathrm{K}^{+}$relative to WT plants under salt treatment. Therefore, faster $\mathrm{H}^{+}$and $\mathrm{Na}^{+}$efflux in the roots also resulted in retention of more $\mathrm{K}^{+}$and a lower $\mathrm{Na}^{+}$concentration in cytosol of SpSOS1-SpAHA1 co-transgenic Arabidopsis plants compared to plants expressing SpSOS1 or SpAHA1 alone (Figs. 3 and 4). This led to Arabidopsis plants co-expressing SpSOS1 and SpAHA1 to have higher a $\mathrm{K}^{+}$/ $\mathrm{Na}^{+}$level than the transgenic plants with only SpSOS1 or SpAHA1, which is strong evidence of salt tolerance. These results suggest SOS1 and AHA1 facilitate more efficient prevention of $\mathrm{K}^{+}$loss and enhance $\mathrm{Na}^{+}$extrusion and thereby contribute to better salt tolerance.

Another deleterious effect of salinity stress in plants is associated with oxidative stress [39]. Accumulation of ROS (reactive oxygen species) is toxic in cells. Therefore, intracellular ROS levels are tightly regulated under normal conditions through a number of intracellular peroxidative and antioxidative reactions within the cell. Salinity can disrupt the ROS production and scavenging balance, resulting in ROS accumulation, which can negatively affect cellular structures and metabolism [63, 64]. In order to protect cells from salinity-induced oxidative damage, excess ROS is scavenged by antioxidant molecules and enzymes. RCD1 (Radical-induced cell death) is a regulator of responses to oxidative stress and protects cells from oxidative damage caused by $\mathrm{H}_{2} \mathrm{O}_{2}$, diamide, and tert-butyl peroxide [65-67]. SOS1 functions in tolerance to oxidative stress by interacting with RCD1 and regulating expression of certain genes associated with oxidative-stress tolerance in Arabidopsis [66]. Haem oxygenase $(\mathrm{HO})$ is an important factor in plant antioxidant defense systems. Overexpression of the AtHO gene enhances Arabidopsis tolerance to salt by increasing PM $\mathrm{H}^{+}$-ATPase activity and expression [68]. Excess ROS can damage membrane structures by oxidizing lipids in the PM, leading some key metabolites abnormally leak out of cells. ROS could disturb ion homeostasis in cells by inducing the efflux of several cations [69-71]. Coskun et al. [53] found $\mathrm{NaCl}$-induced efflux of $\mathrm{K}^{+}$was a result of a lack of PM integrity in rice. This indicates the maintenance of PM stability has a key role in plant salt tolerance. In the present investigation, both SpSOS1 and SpAHA1 prevented the accumulation of MDA in transgenic plants following $\mathrm{NaCl}$ treatment, but plants co-expressing SpSOS1 and SpAHA1 had a more drastic decrease in MDA content under salt stress than plants expressing only one of these genes. This suggests SpSOS1 and SpAHA1 coordinate in transgenic Arabidopsis and ameliorate salt toxicity by more efficiently alleviating oxidative damage to the PM generated by salinity stress.

\section{Conclusions}

Arabidopsis plants co-expressing SpSOS1 and SpAHA1 had higher $\mathrm{K}^{+}$and lower MDA levels than plants transformed with only SpSOS1 or SpAHA1 and, thus, grew better under salt stress. The coordinated action of these genes might be a novel and effective method for increasing the salt tolerance of crops.

\section{Methods}

\section{Plasmid construction}

The SpAHA1 and SpSOS1 genes were separately cloned from S. portulacastrum and inserted into plasmids p414 (p414-SpAHA1) and p416 (p416-SpSOS1) in our recent investigation [3]. Plant vectors expressing SpAHA1 or SpSOS1 alone or together bicistronicly were constructed as described in Additional file 4: Figure S4. (1) Amplification of the SpSOS1 gene was performed using the p416-SpSOS1 plasmid as the template and the primers SpSOS1-F and SpSOS1-R (Additional file 5: Table S1). The amplified gene was inserted into the pCAMBIA1300 vector between $\mathrm{Sal}$ I and $\mathrm{Kpn}$ I restriction sites, generating pCAMBIA1300-SpSOS1. (2) A fragment containing a constitutive promoter (cauliflower mosaic virus $35 \mathrm{~S}$ promoter), the SpSOS1 gene, and the NOS terminator was excised from the pCAMBIA1300-SpSOS1 plasmid using Pst I and EcoR I restriction enzymes and transferred into the plant expression vector pCAMBIA1304 between the same restriction sites. The resulting plasmid 
was named pCAMBIA1304-SpSOS1. (3) The SpAHA1 gene was amplified using the p414-SpAHA1 plasmid as the template and the primers SpAHA1-F and SpAHA1-R (Additional file 5: Table S1) and inserted into the pCAMBIA1304 and pCAMBIA1304-SpSOS1 plasmids between the Spe I and Eco72 I restriction sites to replace the GUS ( $\beta$-glucuronidase) gene. The resulting plasmids were designated PCAMBIA1304-SpAHA1 and pCAMBIA1304-SpSOS1-SpAHA1, respectively. The plasmids were all verified by sequencing.

\section{Arabidopsis transformation and identification}

The three recombinant plasmids described above were added to a $100 \mathrm{mM} \mathrm{CaCl}$ solution containing competent Agrobacterium tumefaciens GV3101 cells. The plasmids were then introduced into the Agrobacterium cells via heat shock $\left(42^{\circ} \mathrm{C}\right)$. Finally, the above three expression cassettes were transformed into Arabidopsis thaliana (Col-0) by infecting flower buds with the Agrobacterium cells containing the recombinant plasmids [72]. T0-generation seeds were screened initially on MS (Murashige \& Skoog) medium supplemented with $50 \mu \mathrm{g} / \mathrm{mL}$ hygromycin B. DNA was purified from the candidate lines and used as template for PCR (polymerase chain reaction) amplification with specific primer pairs to identify the different transgenic plants. The primers are listed in Additional file 5: Table S1. All the transgenic lines were furthermore verified by PCR using primers specific for the $h y g B$ marker gene, HygB-TF and HygB-TR (Additional file 5: Table S1). Total RNA was purified from the transgenic lines and SpAHA1 and SpSOS1 expression was assessed by RT-PCR (reverse transcription PCR) with a housekeeping gene, Actin, as an internal control. The primers for the SpAHA1 (SpAHA1-RT-F and SpAHA1-RT-R), SpSOS1 (SpSOS1-RT-F and SpSOS1-RT-R), and Actin (Actin-RT-F and Actin-RT-F) genes are listed in Additional file 5: Table S1. The PCR conditions were as follows: $94{ }^{\circ} \mathrm{C}$ for $2 \mathrm{~min}$, followed by 28 cycles of $94^{\circ} \mathrm{C}$ for $30 \mathrm{~s}, 55^{\circ} \mathrm{C}$ for $30 \mathrm{~s}$, and $72{ }^{\circ} \mathrm{C}$ for $30 \mathrm{~s}$, and a final extension at $72{ }^{\circ} \mathrm{C}$ for $5 \mathrm{~min}$. The resulting PCR products were assessed by agarose gel electrophoresis.

\section{Cultivation and salt treatment of transgenic and WT plants}

To analyze the salt tolerance of transgenic and WT plants, seeds from T3 homozygous transgenic lines (expressing single SpSOS1, single SpAHA1, and both SpSOS1 and SpAHA1) and untransformed plants were germinated on MS plates in a growth chamber $\left(22^{\circ} \mathrm{C}\right.$ with a $16 \mathrm{~h} \mathrm{light} \mathrm{/} 8 \mathrm{~h}$ dark cycle and a light intensity of $\left.100 \mu \mathrm{mol} \cdot \mathrm{m}^{-2} \cdot \mathrm{s}^{-1}\right)$. After 5 days, the seedlings grown on MS plates were transferred onto MS plates containing 0, 50,75 , and $100 \mathrm{mM} \mathrm{NaCl}$ and allowed to grow for 2 weeks. Then the root length, number of lateral roots, and fresh seedling weights were measured. In addition, 10-day-old seedlings were transferred to a mixture of organic soil and sand $(3: 1, v / v)$ in pots (4 seedlings/pot) and grown in a greenhouse with long-day conditions $(16 \mathrm{~h}$ light $/ 8 \mathrm{~h}$ dark at $22{ }^{\circ} \mathrm{C}$ and a light strength of $150 \mu \mathrm{mol} \cdot \mathrm{m}^{-}$ ${ }^{2} \cdot \mathrm{s}^{-1}$ ) for 4 weeks. The pots containing the plants were then put into water containing 0 or $200 \mathrm{mM} \mathrm{NaCl}$. Ten days post- $\mathrm{NaCl}$ treatment, the treated plants were photographed and their fresh weights were determined.

\section{Determination of $\mathrm{Na}^{+}$and $\mathrm{K}^{+}$content in Arabidopsis plants}

At the end of the $\mathrm{NaCl}$ treatment, the WT and transgenic plants were separately collected. The $\mathrm{Na}^{+}$and $\mathrm{K}^{+}$ in the samples were measured using atomic absorption spectrometry as described in a previous work [31].

\section{Measurement of $\mathrm{Na}^{+}$and $\mathrm{H}^{+}$flux in roots}

Seven-day-old uniform T3 seedlings, which had been grown on MS plates, were transferred to MS medium containing $100 \mathrm{mM} \mathrm{NaCl}$ and grown for 3 days, and then the roots of salt stressed seedlings were put into measurement buffer to balance for $10 \mathrm{~min}$, after that net $\mathrm{H}^{+}$and $\mathrm{Na}^{+}$fluxes were measured in the YoungerUSA Xuyue (Beijing) BioFunction Institute by using Non-invasive Micro-test Technology (NMT100 Series, Xuyue (Beijing) Sci. \& Tech. Co., Ltd., Beijing, China) Software.

$\mathrm{H}^{+}, \mathrm{Na}^{+}$-selective microsensors were prepared as described previously [60]. Pre-pulled and silanized microsensor $(\Phi 4.5 \pm 0.5 \mu \mathrm{m}$, XY-CGQ-01, YoungerUSA) were first filled with a backfilling solution $\left(\mathrm{H}^{+}: 15 \mathrm{mM} \mathrm{NaCl}\right.$ $+40 \mathrm{mM} \mathrm{KH} \mathrm{KO}_{4}, \mathrm{pH} 7.0 ; \mathrm{Na}^{+}: 250 \mathrm{mM} \mathrm{NaCl}$ ) to a length of approximately $1.0 \mathrm{~cm}$ from the tip. Then the microsensors were front filled with $40-50 \mu \mathrm{m}$ columns of selective liquid ion-exchanger (LIX) $\left(\mathrm{H}^{+}\right.$: XY-SJ-H; $\mathrm{Na}^{+}$: XY-SJ-Na; all from YoungerUSA). An Ag/AgCl wire microsensor holder YG003-Y11 (YoungerUSA) was inserted in the back of the microsensor to make electrical contact with the electrolyte solution. YG003-Y11 (YoungerUSA) was used as the reference microsensor. Prior to the flux measurement, the microsensor were calibrated with cultural media having different concentrations of $\mathrm{H}^{+}$(pH 6.0 and $\left.\mathrm{pH} 7.0\right)$ or $\mathrm{Na}^{+}(5 \mathrm{mM}$ and $0.5 \mathrm{mM}$ ), respectively. Only microsensor with a Nernstian slope $>50 \mathrm{mV} /$ decade were used in our study. The same microsensors were calibrated again according to the same procedure and standards after each test. After that, net ion fluxes were recorded on the root meristematic zones, $120 \mu \mathrm{m}$ from the tip where SOS1 activity was the highest [73], in $5 \mathrm{~mL}$ measurement buffer $(0.1 \mathrm{mM}$ $\mathrm{KCl}, 0.1 \mathrm{mM} \mathrm{CaCl} 2,0.1 \mathrm{mM} \mathrm{MgCl}, 0.5 \mathrm{mM} \mathrm{NaCl}, 0.3$ $\mathrm{mM}$ MES (2-(N-Morpholino) ethanesulfonic acid) and $0.2 \mathrm{mM} \mathrm{Na} \mathrm{SO}_{4}, \mathrm{pH} 6.5$ ). Net $\mathrm{H}^{+}$and $\mathrm{Na}^{+}$flux was 
calculated by Fick's law of diffusion [60]. Six biological repeats were performed for each analysis.

\section{Assays of malondialdehyde content}

Two-week-old T3 transgenic and untransformed Arabidopsis seedlings were grown in the presence of $200 \mathrm{mM}$ $\mathrm{NaCl}$ for 7 days. Malondialdehyde (MDA) content in the leaves was measured using the thiobarbituric acid method previously described by Dhindsa and Matowe [74].

\section{Statistical analysis}

Two-tailed Student's t-tests were used to analyze the data. The results are expressed as mean $\pm \mathrm{SE}$ and differences with a $P$-value $<0.05$ were considered statistically significant. At least three biological replicates were performed for each experiment.

\section{Additional files}

Additional file 1: Figure S1. Molecular identification of transgenic plants. DNA was purified from transgenic and WT plant leaves. (a) PCR identification of SpSOS1 transgenic plants. M: DL2000 marker (Sangon Biotech, China; No. B600335); 1-12, different transgenic lines (lines 1-12); 13, negative control (WT plants). (b) PCR identification of SpAHA1 transgenic plants. M: DL2000 marker; 1-11, different transgenic lines (lines 1-11); 12, negative control (WT plants). (c) PCR identification of SpSOS1 and SpAHA1 co-expressing plants. M: DL2000 marker; 1-10, different transgenic lines (lines 1-10); 11, negative control (WT plants). PCR amplification was performed using primers specific for SpSOS1, SpAHA1, or hygB gene (expected sizes of 980, 916, and 750 bp, respectively) with the corresponding DNA serving as the template. The PCR products were assessed by agarose gel electrophoresis. (TIF $835 \mathrm{~kb}$ )

Additional file 2: Figure S2. Expression of SpSOS1 and SpAHA1 genes in transgenic Arabidopsis lines. Total RNA was purified from leaves from the T3 generation of transgenic plants and used for RT-PCR analysis. The Arabidopsis Actin gene served as an internal control. (a) Expression of the SpSOS1 gene in SpSOS1-transgenic plants was analyzed by RT-PCR. 1-12, different transgenic lines (lines 1-12). (b) Expression of SpAHA1 gene in SpAHA1-transgenic plants as analyzed by RT-PCR. 1-11, different transgenic lines (lines 1-11). (c) Expression of SpSOS1 and SPAHA1 genes in SPSOS1-SPAHA1 co-expressing plants as analyzed by RT-PCR. 1-10, different transgenic lines (lines 1-10). (TIF $531 \mathrm{~kb}$ )

Additional file 3: Figure S3. $\mathrm{Na}^{+}$flux in roots of Arabidopsis plants grown in media without $\mathrm{NaCl}$. $\mathrm{Na}^{+}$flux in the roots of seven-day-old seedlings was measured using the NMT technique described in the Methods section. (a) Changes in the NMT signals are expressed as arbitrary units. (b) $\mathrm{Na}^{+}$flux is expressed as the amount of efflux per second per square centimeter $\left(\mathrm{pmol} \cdot \mathrm{cm}^{-2} \cdot \mathrm{s}^{-1}\right)$. Data are presented as mean \pm SE of three replicates. Same letter above the columns indicate that the differences at a $p<0.05$ level among the different experimental cohorts are not significant statistically. SpSOS1, SpSOS1-overexpressing plants; SpAHA1, SpAHA1-overexpressing plants; SpSOS1-SpAHA1, SpSOS1 and SpAHA1 co-expressing plants; WT, wild-type plants. (TIF $456 \mathrm{~kb}$ )

Additional file 4: Figure S4. Schematic of T-DNA region in the binary vectors. (a) The pCAMBIA1300-SpSOS1, (b) T pCAMBIA1304-SpSOS1, (c) pCAMBIA1304-SpSOS1-SpAHA1, and (d) pCAMBIA1304-SpAHA1 plasmids. (TIF $239 \mathrm{~kb}$ )

Additional file 5: Table S1. Sequences of primers used in this study. Small letters indicate restriction enzyme sites. (XLS 18 kb)

\section{Abbreviations}

AHA: $\mathrm{H}^{+}$-ATPase; AVPNP: Vacuolar $\mathrm{H}^{+}$-PPase; GUS: $\beta$-glucuronidase; HA: $\mathrm{H}^{+}$ATPase; $\mathrm{HO}$ : Haem oxygenase; KOR: $\mathrm{K}^{+}$outward rectifier; MDA: Malondialdehyde; MES: 2-(N-Morpholino) ethanesulfonic acid;
MS: Murashige \& Skoog; NHX: $\mathrm{Na}^{+} / \mathrm{H}^{+}$antiporter; NSCC: Non-selective cation channels; PCR: Polymerase chain reaction; PM: Plasma membrane; RCD: Radical-induced cell death; RNAi: RNA interference; ROS: Reactive oxygen species; RT-PCR: Reverse transcription polymerase chain reaction; SOS: Salt overly sensitive; WT: Wild-type

\section{Acknowledgements}

We thank Boston Professional Group (BPG) Editing for English language editing. We also thank the reviewers and editors for helpful comments on earlier drafts of the manuscript.

\section{Funding}

This work was supported by the National Natural Science Foundation of China (31660253 to XJ), the Scientific and Technological Foundation of Hainan Province (HNGDhs201502 to XJ), the Foundations of Hainan University and Shandong Normal University (hdkytg201706 to XJ and JS), and Startup funding from Hainan University (KYQD(ZR) 1845 to YZ). The above funding was used for the design of the study and collection, analysis, and interpretation of data in writing the manuscript.

\section{Availability of data and materials}

The datasets used and/or analyzed during the current study are available from corresponding authors on reasonable request.

\section{Authors' contributions}

$X J, Y Z$ and $Z W$ conceived and designed the experiments. YF, $X Y, Q X$ and $Y X$ performed the experiments. YZ and JS made substantial contributions to the data analysis. XJ and JS supervised, wrote and revised the manuscript. All authors read and approved the final manuscript.

Ethics approval and consent to participate

Not applicable.

\section{Consent for publication}

Not applicable.

\section{Competing interests}

The authors declare that they have no competing interests.

\section{Publisher's Note}

Springer Nature remains neutral with regard to jurisdictional claims in published maps and institutional affiliations.

\section{Author details}

${ }^{1}$ Hainan Key Laboratory for Sustainable Utilization of Tropical Bioresources /Institute of Tropical Agriculture and Forestry, Hainan University, Haikou 570228, China. ${ }^{2}$ Shandong Key Laboratory of Plant Stress/College of Life Science, Shandong Normal University, Jinan 250014, China.

Received: 17 August 2018 Accepted: 7 February 2019

Published online: 14 February 2019

\section{References}

1. Kronzucker HJ, Coskun D, Schulze LM, Wong JR, Britto DT. Sodium as nutrient and toxicant. Plant Soil. 2013;369:1-23.

2. Flowers TJ, Colmer TD. Salinity tolerance in halophytes. New Phytol. 2008; 179:945-63.

3. Zhou Y, Yin X, Duan R, Hao G, Guo J, Jiang X. SpAHA1 and SpSOS1 coordinate in transgenic yeast to improve salt tolerance. PLoS One. 2015;10: e0137447.

4. Fuglsang AT, Paez-Valencia J, Gaxiola RA. Plant proton pumps: regulatory circuits involving $\mathrm{H}^{+}$-ATPase and $\mathrm{H}^{+}$-PPase. In: Geisler $\mathrm{M}$, Venema $\mathrm{K}$, editors. Transporters and pumps in plant signaling. Berlin: Springer; 2010. p. 39-64.

5. Gaxiola RA, Palmgren MG, Schumacher K. Plant proton pumps. FEBS Lett. 2007:581:2204-14

6. Arango M, Gevaudant F, Oufattole M, Boutry $M$. The plasma membrane proton pump ATPase: the significance of gene subfamilies. Planta. 2003;216: $355-65$.

7. Axelsen $\mathrm{KB}$, Palmgren MG. Inventory of the superfamily of P-type ion pumps in Arabidopsis. Plant Physiol. 2001;126:696-706. 
8. Bose J, Rodrigo-Moreno A, Lai D, Xie Y, Shen W, Shabala S. Rapid regulation of the plasma membrane $\mathrm{H}^{+}$-ATPase activity is essential to salinity tolerance in two halophyte species, Atriplex lentiformis and Chenopodium quinoa. Ann Bot. 2015;115:481-94.

9. Ding M, Hou P, Shen X, Wang M, Deng S, Sun J, Xiao F, Wang R, Zhou X, Lu $C$, et al. Salt-induced expression of genes related to $\mathrm{Na}^{+} / \mathrm{K}^{+}$and $\mathrm{ROS}$ homeostasis in leaves of salt-resistant and salt sensitive poplar species. Plant Mol Biol. 2010;73:251-69.

10. Niu X, Narasimhan M, Salzman R. NaCl regulation of plasma membrane $\mathrm{H}^{+}$ATPase gene expression in glycophyte and halophyte. Plant Physiol. 1993; 103:712-8.

11. Sahu B, Shaw B. Salt-inducible isoform of plasma membrane $\mathrm{H}^{+}$-ATPase gene in rice remains constitutively expressed in natural halophyte, Suaeda maritime. J Plant Physiol. 2009;166:1077-89.

12. Chen $\mathrm{M}$, Song J, Wang $\mathrm{B}$. $\mathrm{NaCl}$ increases the activity of the plasma membrane $\mathrm{H}^{+}$-ATPase in C3 halophyte Suaeda salsa callus. Acta Physiol Plant. 2010;36:27-36

13. Lopez-Pérez L, Martinez-Ballesta M, Maurel C, Carvajal M. Changes in plasma membrane lipids, aquaporins and proton pump of broccoli roots, as an adaptation mechanism to salinity. Phytochemistry. 2009;70:492-500.

14. Palmgren MG. Plant plasma membrane H1-ATPases: powerhouses for nutrient uptake. Annu Rev Plant Physiol Plant Mol Biol. 2001;52:817-45.

15. Pons R, Cornejo MJ, Sanz A. Differential salinity-induced variations in the activity of $\mathrm{H}^{+}$-pumps and $\mathrm{Na}^{+} / \mathrm{H}^{+}$antiporters that are involved in cytoplasm ion homeostasis as a function of genotype and tolerance level in rice cell lines. Plant Physiol Biochem. 2011;49:1399-409.

16. Vitart V, Baxter I, Doerner P, Harper JF. Evidence for a role in growth and salt resistance of a plasma membrane $\mathrm{H}^{+}$-ATPase in the root endodermis. Plant J. 2001;27:191-201.

17. Gevaudant F, Duby G, Stedingk E, Zhao R, Morsomme P, Boutry M. Expression of a constitutively activated plasma membrane $\mathrm{H}^{+}$-ATPase alters plant development and increases salt tolerance. Plant Physiol. 2007;144:1763-76.

18. Wu SJ, Ding L, Zhu JK. SOS1, a genetic locus essential for salt tolerance and potassium acquisition. Plant Cell. 1996;8:617-27.

19. Xu H, Jiang $X$, Zhan $K$, Cheng $X$, Chen $X$, Pardo JM, Cui D. Functional characterization of a wheat plasma membrane $\mathrm{Na} / \mathrm{H}$ antiporter in yeast. Arch Biochem Biophys. 2008;473:8-15.

20. Oh DH, Leidi E, Zhang Q, Hwang SM, Li Y, Quintero FJ, Jiang X, D'Urzo MP, Lee SY, Zhao Y, et al. Loss of halophytism by interference with SOS1 expression. Plant Physiol. 2009;151:210-22.

21. Olias R, Eljakaoui Z, Li J, Morales PA, Marin-Manzano MC, Pardo JM, Blelver A. The plasma membrane $\mathrm{Na}^{+} / \mathrm{H}^{+}$antiporter SOS1 is essential for salt tolerance in tomato and affects the partitioning of $\mathrm{Na}^{+}$between plant organs. Plant Cell Environ. 2009;32:904-16.

22. Tang RJ, Liu H, Bao Y, Lv QD, Yang L, Zhang $H$. The woody plant poplar has a functionally conserved salt overly sensitive pathway in response to salinity stress. Plant Mol Biol. 2010;74:367-80.

23. Fraile-Escanciano A, Kamisugi Y, Cuming AC, Rodríguez-Navarro A, Benito B. The SOS1 transporter of Physcomitrella patens mediates sodium efflux in planta. New Phytol. 2010;188:750-61.

24. Feki K, Quintero FJ, Pardo JM, Masmoudi K. Regulation of durum wheat $\mathrm{Na}^{+}$/ $\mathrm{H}^{+}$exchanger TdSOS1 by phosphorylation. Plant Mol Biol. 2001;76:545-56.

25. Li Q, Tang Z, Hu Y, Yu L, Liu Z, Xu G. Functional analyses of a putative plasma membrane $\mathrm{Na}^{+} / \mathrm{H}^{+}$antiporter gene isolated from salt tolerant Helianthus tuberosus. Mol Biol Rep. 2014;41:5097-108.

26. Quintero FJ, Martinez-Atienza J, Villalta I, Jiang X, Kim MY, Ali Z, Fujii H, Mendoza I, Yun DJ, Zhu JK, et al. Activation of the plasma membrane $\mathrm{Na} / \mathrm{H}$ antiporter salt-overly-sensitive 1 (SOS1) by phosphorylation of an autoinhibitory C-terminal domain. Proc Natl Acad Sci U S A. 2011;108:2611-6.

27. Martinéz-Atienza J, Jiang X, Garciadeblas B, Mendoza I, Zhu JK, Pardo JM, Quintero FJ. Conservation of the salt overly sensitive pathway in rice. Plant Physiol. 2007;143:1001-12.

28. Shi H, Ishitani M, Kim C, Zhu JK. The Arabidopsis thaliana salt tolerance gene SOS1 encodes a putative $\mathrm{Na}^{+} / \mathrm{H}^{+}$antiporter. Proc Natl Acad Sci U S A. 2000; 97:6896-901.

29. Zhu JK, Liu J, Xiong L. Genetic analysis of salt tolerance in Arabidopsis: evidence for a critical role of potassium nutrition. Plant Cell. 1998;10:1181-91.

30. Shi H, Lee BH, Wu SJ, Zhu J. Overexpression of a plasma membrane $\mathrm{Na}^{+} / \mathrm{H}^{+}$ antiporter gene improves salt tolerance in Arabidopsis thaliana. Nat Biotechnol. 2003;21:81-5.
31. Zhou Y, Lai Z, Yin X, Yu S, Xu Y, Wang X, Cong X, Luo Y, Xu H, Jiang X. Hyperactive mutant of a wheat plasma membrane $\mathrm{Na}^{+} / \mathrm{H}^{+}$antiporter improves the growth and salt tolerance of transgenic tobacco. Plant Sci. 2016:253:176-86.

32. Yi XP, Sun Y, Yang Q, Guo AP, Chang LL, Wang D, Tong Z, Jin X, Wang LM, $Y u J L$, et al. Quantitative proteomics of Sesuvium portulacastrum leaves revealed that ion transportation by V-ATPase and sugar accumulation in chloroplast played crucial roles in halophyte salt tolerance. J Proteome. 2014:99:84-100.

33. Slama I, Ghnaya T, Savoure A, Abdelly C. Combined effects of longterm salinity and soil drying on growth, water relations, nutrient status and proline accumulation of Sesuvium portulacastrum. C R Biol. 2008; 331:442-51.

34. Rabhi M, Ferchichi S, Jouini J, Hamrouni MH, Koyro HW, Ranieri A, Abdelly C, Smaoui A. Phytodesalination of a salt-affected soil with the halophyte Sesuvium portulacastrum L. to arrange in advance the requirements for the successful growth of a glycophytic crop. Bioresour Technol. 2010;101:6822-8.

35. Lokhande VH, Nikam TD, Suprasanna P. Biochemical, physiological and growth changes in response to salinity in callus cultures of Sesuvium portulacastrum L. Plant Cell Tiss Org. 2010;102:17-25.

36. Nawaz I, labl M, Hakvoort HWJ, Bliek M, de Boer B, Schat H. Expression levels and promoter activities of candidate salt tolerance genes in halophyte and glycophytic Brassicaceae. Environ Exp Bot. 2014;99:59-66.

37. Fan Y, Wan S, Jiang Y, Xia Y, Chen X, Gao M, Cao Y, Luo Y, Zhou Y, Jiang X. Over-expression of a plasma membrane $\mathrm{H}^{+}$-ATPase SpAHA1 conferred salt tolerance to transgenic Arabidopsis. Protoplasma. 2018;255:1827-37.

38. Zhou Y, Yin X, Wan S, Hu Y, Hu Y, Xie Q, Li R, Zhu B, Fu S, Guo J, Jiang X. The Sesuvium portulacastrum plasma membrane $\mathrm{Na}^{+} / \mathrm{H}^{+}$antiporter SpSOS1 complemented the salt sensitivity of transgenic Arabidopsis sos 1 mutant plants. Plant Mol Biol Rep. 2018;36:553-63.

39. Mansour MMF. The plasma membrane transport systems and adaptation to salinity. J Plant Physiol. 2014;171:1787-800.

40. Fuglsang AT, Guo Y, Cuin TA, Qiu Q, Song C, Kristiansen KA, Bych K, Schulz A, Shabala S, Schumaker KS, et al. Arabidopsis protein kinase PKS5 inhibits the plasma membrane $\mathrm{H}^{+}$-ATPase by preventing interaction with 14-3-3 protein. Plant Cell. 2007;19:1617-34.

41. Munns R, Tester M. Mechanism of salinity tolerance. Annu Rev Plant Biol. 2008;59:651-81.

42. Wu GQ, Feng RJ, Wang SM, Wang CM, Bao AK, Wei L, Yuan HJ. Coexpression of xerophyte Zygophyllum xanthoxylum ZxNHX and ZxVP1-1 confers enhanced salinity tolerance in chimeric sugar beet (Beta vulgaris L.). Front Plant Sci. 2015:6:581.

43. Hedrich R, Shabala S. Stomata in a saline world. Curr Opin Plant Biol. 2018; 46:87-95.

44. Almeida DM, Oliveira MM, Saibo NJM. Regulation of $\mathrm{Na}^{+}$and $\mathrm{K}^{+}$ homeostasis in plants: towards improved salt stress tolerance in crop plants. Genet Mol Biol. 2017:40:326-45.

45. Bao AK, Wang YW, Xi JJ, Liu C, Zhang Jl, Wang SM. Co-expression of xerophyte Zygophyllum xanthoxylum ZxNHX and ZxVP1-1 enhances salt and drought tolerance in transgenic Lotus corniculatus by increasing cations accumulation. Funct Plant Biol. 2014:41:203-14.

46. Zhao FY, Zhang XJ, Li PH, Zhao YX, Zhang H. Co-expression of the Suaeda salsa SsNHX1 and Arabidopsis AVP1 confer greater salt tolerance to transgenic rice than the single SsNHX1. Mol Breeding. 2006;17:341-53.

47. Liu SP, Zheng LQ, Xue YH, Zhang Q, Wang L, Shou HX. Overexpression of OsVP1 and OsNHX1 increases tolerance to drought and salinity in rice. J Plant Biol. 2010;53:444-52.

48. Gouiaa S, Khoudi H, Leidi EO, Pardo JM, Masmoudi K. Expression of wheat $\mathrm{Na}^{+} / \mathrm{H}^{+}$antiporter TNHXS1 and $\mathrm{H}^{+}$-pyrophosphatase TVP1 genes in tobacco from a bicistronic transcriptional unit improves salt tolerance. Plant Mol Biol. 2012:79:137-55.

49. Upadhyay A, Upadhyay AK, Bhirangi R. Expression of $\mathrm{Na}^{+} / \mathrm{H}^{+}$antiporter gene in response to water and salinity stress in grapevine rootstocks. Biol Plant. 2012;56:762-6.

50. Yadav NS, Shukla P, Jha A, Agarwal P, Jha B. The SbSOS1 gene from the extreme halophyte Salicornia brachiata enhances $\mathrm{Na}^{+}$loading in xylem and confers salt tolerance in transgenic tobacco. BMC Plant Biol. 2012;12:188.

51. Yang Q, Chen Z, Zhou X, Yin H, Xin X, Hong X, Zhu JK, Gong ZZ. Overexpression of SOS (salt overly sensitive) genes increases salt tolerance in transgenic Arabidopsis. Mol Plant. 2009;2:22-31. 
52. Wang $M$, Wang $Y$, Sun J, Ding $M$, Deng $S$, Hou $P$, Ma $X$, Zhang $Y$, Wang $F$, $\mathrm{Sa} \mathrm{G}$, et al. Overexpression of PeHA1 enhances hydrogen peroxide signaling in salt-stressed Arabidopsis. Plant Physiol Biochem. 2013;71:37-48.

53. Coskun D, Britto D, Jean Y, Kabir I, Tolay I, Torun AA, Kronzucker HJ. K+ efflux and retention in response to $\mathrm{NaCl}$ stress do not predict salt tolerance in contrasting genotypes ofrice (Oryza sativa L.). PLoS One. 2013;8:e57767.

54. Barragan V, Leidi EO, Andrés Z, Rubio L, De Luca A, Fernandez JA, Cubero B, Pardo JM. lon exchangers NHX1 and NHX2 mediate active potassium uptake into vacuoles to regulate cell turgor and stomatal function in Arabidopsis. Plant Cell. 2012;24:1127-42.

55. Marschner H. Mineral nutrition of higher plants. Ann Bot. 1995;78:527-8.

56. Duggleby RG, Dennis DT. Pyruvate kinase, a possible regulatory enzyme in higher plants. Plant Physiol. 1973;52:312-7.

57. Maathuis FJM, Amtmann A. $\mathrm{K}^{+}$nutrition and $\mathrm{Na}^{+}$toxicity: the basis of cellular $\mathrm{K}^{+} / \mathrm{Na}^{+}$ratios. Ann Bot. 1999:84:123-33.

58. Lutts S, Kinet J, Bouharmont J. NaCl-induced senescence in leaves of rice (Oryza sativa L.) cultivars differing in salinity resistance. Ann Bot. 1996;78: 389-98.

59. Tester $\mathrm{M}$, Davenport RJ. $\mathrm{Na}^{+}$tolerance and $\mathrm{Na}^{+}$transport in higher plants. Ann Bot. 2003:91:503-27.

60. Sun J, Dai S, Wang R, Chen S, Li N, Zhou X, Lu C, Shen X, Zheng X, Hu Z, et al. Calcium mediates root $\mathrm{K}^{+} / \mathrm{Na}^{+}$homeostasis in poplar species differing in salt tolerance. Tree Physiol. 2009;29:1175-86.

61. Horie T, Karahara I, Katsuhara M. Salinity tolerance mechanisms in glycophytes: an overview with the central focus on rice plants. Rice. 2012;5:11.

62. Qi Z, Spalding EP. Protection of plasma membrane $\mathrm{K}^{+}$transport by the salt overly sensitive1 $\mathrm{Na}^{+} / \mathrm{H}^{+}$antiporter during salinity stress. Plant Physiol. 2004; 136:2548-55.

63. Chaves MM, Oliveira MM. Mechanisms underlying plant resilience to water deficits: prospects for water-saving agriculture. J Exp Bot. 2004;55:2365-84

64. Chaves MM, Flexas J, Pinheiro C. Photosynthesis under drought and salt stress: regulation mechanisms from whole plant to cell. Ann Bot. 2009;103: 551-60.

65. Belles-Boix E, Babiychuk E, Van Montagu M, Inze D, Kushnir S. CEO1 a new protein from Arabidopsis thaliana, protects yeast against oxidative damage. FEBS Lett. 2000;482:19-24.

66. Katiyar-Agarwal S, Zhu J, Kim K, Agarwal M, Fu X, Huang A, Zhu JK. The plasma membrane $\mathrm{Na}^{+} / \mathrm{H}^{+}$antiporter SOS1 interacts with $\mathrm{RCD} 1$ and functions in oxidative stress tolerance in Arabidopsis. Proc Natl Acad Sci U S A. 2006;103:18816-21.

67. Overmyer K, Tuominen H, Kettunen R, Betz C, Langebartels C, Sandermann $\mathrm{HJ}$, Kangasjarvi J. Ozone-sensitive Arabidopsis rcd1 mutant reveals opposite roles for ethylene and jasmonate signaling pathways in regulating superoxide-dependent cell death. Plant Cell. 2000;12:1849-62.

68. Bose J, Xie Y, Shen W, Shabala S. Haem oxygenase modifies salinity tolerance in Arabidopsis by controlling $\mathrm{K}^{+}$retention via regulation of the plasma membrane $\mathrm{H}^{+}$-ATPase and by altering SOS1 transcript levels in roots. J Exp Bot. 2013:64:471-81.

69. Demidchik V, Cuin TA, Svistunenko D, Smith SJ, Miller AJ, Shabala S, Sokolik A, Yurin V. Arabidopsis root $\mathrm{K}^{+}$-efflux conductance activated by hydroxyl radicals: single-channel properties, genetic basis and involvement in stressinduced cell death. J Cell Sci. 2010;123:1468-79.

70. Demidchik V, Maathuis FJM. Physiological roles of nonselective cation channels in plants: from salt stress to signalling and development. New Phytol. 2007;175:387-404.

71. Velarde-Buendía AM, Shabala S, Cvikrova M, Dobrovinskaya O. Salt-sensitive and salt-tolerant barley varieties differ in the extent of potentiation of the ROS-induced K+ efflux by polyamines. Plant Physiol Biochem. 2012;61:18-23.

72. Clough SJ, Bent AF. Floral dip: a simplified method for Agrobacteriummediated transformation of Arabidopsis thaliana. Plant J. 1998;16:735-43.

73. Shabala L, Cuin TA, Newman IA, Shabala S. Salinity-induced ion flux patterns from the excised roots of Arabidopsis sos mutants. Planta. 2005;222:1041-50.

74. Dhindsa RS, Matowe W. Drought tolerance in two mosses: correlated with enzymatic defence against lipid peroxidation. J Exp Bot. 1981;32:79-91.

\section{Ready to submit your research? Choose BMC and benefit from:}

- fast, convenient online submission

- thorough peer review by experienced researchers in your field

- rapid publication on acceptance

- support for research data, including large and complex data types

- gold Open Access which fosters wider collaboration and increased citations

- maximum visibility for your research: over $100 \mathrm{M}$ website views per year

At BMC, research is always in progress.

Learn more biomedcentral.com/submissions 